\title{
Islamisasi Ilmu Pengetahuan Syed Muhammad Naquib Al-Attas Dan Isma'Il Raji Al-Faruqi
}

Ruchhima

Mahasiswi Pasca Sarjana Program Studi Hukum Ekonomi Syariah, Universitas Darussalam Gontor e-mail: ruchhima27@gmail.com

Abstract: Islamisasi muncul karena kekhawatiran intelektual Muslim yang melibat umat Islam berada dalam krisis akibat penerapan ilmu pengetahuan Barat yang berbasis sekuler. Konsep sekuler dalam ilmu pengetahuan tidake sesuai dengan umat Islam karena memisabkan agama dari ilmu. Intelektual Muslim yang gencar mengagas Islamisasi adalab syed Muhammad Naquib Al-Attas dan Isma'il Raji Al-Faruqi. Keduanya sama-sama beranggapan bahwa ilmu pengetabuan Barat tidak bebas nilai karena berisi ide-ide, nilai-nilai dan doktrin dari kebudayaan dan peradaban Barat. Makalah ini bertujuan untuk. mengetabui latar belakang, konsep, dan langka-langkah dalam proses Islamisasi ilmu menurut pandangan Syed Mubammad Naquib Al-Attas dan Isma'il Raji Al-Faruqi. Makalah ini merupakan penelitian kepustakaan dengan menggunakan metode kualitatif.

Kata kunci: Islamization, consumption theory, modernization 


\section{PENDAHULUAN}

Kemajuan sains modern yang di kembangkan Barat telah membawa pengaruh yang besar dalam dalam dunia keilmuan. Namun, ternyata sains modern yang dikembangkan Barat tersebut juga mebawa implikasi negatif dalam kehidupan manusia terutama masyarakat Muslim. Sains modern dibangun dan dikembangkan dengan dasar sekuler yaitu memisahkan agama dari ilmu pengetahuan. Barat berasumsi bahwa ilmu pengetahuan adalah netral oleh karena itu tidak boleh ada nilai-nilai yang mencampuri termasuk agama. Ilmu pengetahuan Barat yang kering nilai agama ini tidak sesuai dengan kehidupan Muslim yang sarat akan nilai agama. Karena Islam komprehensif, semua kegiatan manusia telah ada ketentuannya termasuk dalam bidang keilmuan. Sehingga apabila umat Muslim menerima begitu saja ilmu pengetahuan yang dikembangkan Barat hanya akan menimbulkan dampak negatif bagi kehidupan mereka. ${ }^{1}$

Dampak negatif yang ditimbulkan dari ilmu pengetahuan Barat berupa kebingunan dan keraguan. Hal ini terjadi karena prinsip dan tujuan Barat dalam memandang ilmu pengetahuan berbeda dengan prinsip dan tujian dalam Islam. Oleh karena itu untuk membebaskan manusia dari kebingungan dan kebuntuan dalam pemikiran dibutuhkan Islamisasi ilmu pengetahuan. Dengan memandang ilmu pengetahuan berdasarkan prinsip-prinsip Islam. ${ }^{2}$ Islamisasi ilmu pengetahuan sebenarnya telah dipraktekkan sejak zaman Rasulullah yaitu dalam mengubah paradigma jahiliyah kepada prinsip rabbaniyyah dan tauhid kepada Allah. Kemudian Islamisasi ilmu diteruskan oleh Sarjana Muslim Klasik seperti penerjemehan karya dari Persia dan Yunani yang diberi pemaknaan ulang sesuai dengan konsep Islam.

Sarjana kontemporer Sayyed Hossein Nasr juga secara terbuka menggagas perspektif sufi sebagai alternatif atas krisis epistemologi. Kemudian gagasan Islamisasi ini dilanjutkan oleh alAttas dan al-Faruqi. ${ }^{3}$ Menurut al-Attas penyebab krisis masyarakat modern adalah ilmu penegtahuan Barat yang bersifat relativistik dan nihilistik dikonsumsi masyarakat modern saat ini. ${ }^{4}$ Al-Faruqi juga beranggapan bahwa krisis timbul akibat diterapkannya sistem pendidikan sekuler Barat yang tidak berlandaskan pada tauhid sehingga mengakibatkan umat Muslim kehilangan tujuan hidupnya. ${ }^{5}$

Dari penjelasan diatas dirasa penting untuk membahas konsep Islamisasi yang digagas oleh Al-Attas dan Al-Faruqi karena pentingnya Islamisasi dan keduanya juga sangat gencar menggagas

1 Zuhdiyah, "Islamisasi Ilmu Ismail Raji Al-Faruqi", Tadrib Vol. Ii No. 2 Edisi Desember 2016, Hlm. 9

2 Syed Muhammad Naquib Al-Attas, " The Consept Of Education In Islam", (Malaysia:International Institute Of Islamic Thought And Civilization (Istac),1980),Hlm.11-12

${ }^{3}$ Muhammad Taufik Dan Muhammad Yasir, "Mengkritisi Konsep Islamisasi Ilmu Ismail Raji Al-Faruqi: Telaah Pemikiran Ziauddin Sardar", Jurnal Ushuluddin Vol. 25 No.2, Juli-Desember 2017, Hlm.114

${ }^{4}$ Ni'Mah Afifah, "Islamisasi Ilmu Pengetahuan Perspektif Naquib Al-Attas Di Tengah Kemunduran Dunia Ilmiah Islam", Modeling: Jurnal Program Studi Pgmi, Hlm. 206

5 Zuhdiyah, "Islamisasi Ilmu Ismail Raji Al-Faruqi", Hlm. 5 
Islamisasi ilmu pengetahuan, maka makalah ini akan membahas latar belakan pemikiran Islamisasi, konsep-konsep, proses Islamisasi dan perbedaan konsep Islamisasi dari keduanya.

\section{PEMBAHASAN}

\section{A. Latar Belakang Islamisasi}

\section{Syed Muhammad Naquib Al-Attas}

Ilmu pengatuhan yang diambil alih oleh Barat dari Islam dikembangkan berlawana dengan nilai-nilai Islam. Barat mengasumsikan bahwa ilmu pengetahuan bebas nilai namun, Al-Attas melihat bahwa ilmu pengetahuan yang ada ini tidak bersifat netral, akan tetapi syarat nilai. Ilmu pengatahuan kontemporer dibentuk dan dikembangkan sesuai dengan nilai-niali kebudayaan dan kebudayaan Barat. Di dalamnya terdapat ide-ide, nila-nilai, kebudayaan, keyakina, filsafat, agama, doktrin berupa spekulasi yang semuanya bertentangan dengan nilainilai dalam Islam. ${ }^{6}$ Karena itu, al-Attas memandang bahwa peradaban Barat tidak layak untuk dikonsumsi sebelum diseleksi terlebih dahulu. ${ }^{7}$

Pengembangan ilmu di Barat dengan tradisi dan kultur yang berbeda dengan kultur Islam yang berbasis ajaran normatif yang tersurat dalam al-Qur'an dan Hadis. Namun Muslim secara tidak sadar mengambil begitu saja ilmu pengatahuan tersebut dan berakhir dengan kebingungan, skeptisisme dan ketergantungan pada pengetahuan barat. Oleh karena itu al-Attas menganggap penting untuk membesaskan manusia dari pemikiran sekuler yang dapat merusaknya. ${ }^{8}$

\section{Isma'Il Raji Al-Faruqi}

Kemajuan Barat membuat umat Muslim tergoda dan berupaya melakukan westernisasi. Namun upaya tersebut sebaliknya menyebabkan krisis ekonomi, sosial dan politik. Menurut Al-Faruqi krisis tersebut akhirnya menimbulakn dualisme dalam sistem pendidikan dan kehidupan umat Islam. Penggunaan sistem pendidikan sekuler Barat ternyata tidak membawa kemajuan. Hal initerjadi karena sistem sekuler memisahkan agama dengan ilmu yang membuat umat Muslim kehilangan tujuannya.

\footnotetext{
${ }^{6}$ Sholeh, "Islamisasi Ilmu Pengetahuan (Konsep Pemikiran Ismail Raji Al-Faruqi Dan Syed Muhammad Naquib Al-Attas)", Jurnal Al-Hikmah Vol. 14, No. 2, Oktober 2017, Hlm.215

7 Anita Mauliyah, "Gerakan Islamisasi Ilmu Pengetahuan Naquib Al-Attas", El-Banat: Jurnal Pemikiran Dan Pendidikan Islam Volume 6, Nomor 1, Januari-Juni 2016, Hlm. 116

${ }^{8}$ Muhammad Taufik Dan Muhammad Yasir, "Mengkritisi Konsep Islamisasi Ilmu Ismail Raji Al-Faruqi: Telaah Pemikiran Ziauddin Sardar", Hlm. 111-112
} 
Oleh karena itu Al-Faruqi menginginkan adanya reformasi di bidang pemikiran Islam. Dengan melakukan Islamisasi ilmu atau integerasi pengetahuan baru dengan warisan Islam, dengan penghilangan, perubahan, penafsiran kembali dan adaptasi komponennya sesuai dengan pandangan dan nilai-nilai Islam. ${ }^{9}$

\section{B. Konsep Islamisasi}

\section{Syed Muhammad Naquib Al-Attas}

Menurut Al-Attas, "Islamisasi adalah pembebasan manusia pertama dari magis, mitologis, animistis, nasional-kultur, dan kemudian dari kontrol sekuler atas nalar dan bahasanya." manusia dalam wujud fisiknya cenderung sekuler dan lupa terhadap hakikat dirinya dan berbuat tidak adil terhadapnya. Ilmu pengetahuan yang dikembangkan peradaban Barat telah menimbulkan kerusakan karena dikembangkan diatas pandangan hidup, budaya dan peradaban Barat dipengaruhi. Oleh karena itu Menurut Al-Attas dalam Islamisasi elemen-elemen yang harus dihilangkan yaitu:

a. mengandalkan akal untuk membimbing kehidupan manusia,

b. bersikap dualistik terhadap realitas dan kebenaran,

c. menegaskan aspek eksistensi yang memproyeksikan kehidupan sekular,

d. membela doktrin humanisme,

e. menjadikan drama dan tragedi sebagai unsur-unsur yang dominan dalam fitrah dan eksistensi manusia.

\section{Isma'Il Raji Al-Faruqi}

Menurut al-Faruqi, Islamisasi ilmu pengetahuan itu sendiri berarti melakukan aktifitas keilmuan seperti eliminasi, perubahan, penafsiran kembali dan penyesuaian terhadap komponenkomponennya sebagai world view Islam (pandangan dunia Islam) dan menetapkan nilai-nilainya. Dengan demikian, islamisasi ilmu pengetahuan dapat diartikan dengan mengislamkan ilmu pengetahuan modern dengan cara menyusun dan membangun ulang sains sastra, dan sains-sains ilmu pasti dengan memberikan dasar dan tujuan-tujuan yang konsisten dengan Islam. Menuangkan kembali ilmu pengetahuan sebagaimana dikehendaki Islam, yaitu memberi definisi baru, mengatur data, mengevaluasi kembali kesimpulan dan memproyeksikan kembali tujuan-

9 Zuhdiyah, "Islamisasi Ilmu Ismail Raji Al-Faruqi", Hlm.4-5

${ }^{10}$ Syed Muhammad Naquib Al-Attas, "Islam And Secularism", (Kuala Lumpur, Art Printing Works Sdn. Bhd, Istac, 1978) Hlm. 41 
tujuannya. ${ }^{11}$ Islamisasi ilmu pengetahuan bertujuan untuk menghasilkan buku-buku pegangan (buku dasar) di perguruan tinggi, dengan menuangkan kembali disiplin ilmu modern ke dalam wawasan Islam, setelah dilakukan kajian kritis terhadap kedua sistem pengetahuan Islam dan Barat. $^{12}$

Al-Faruqi menggunakan prinsip tuhid dalam malakukan Islamisasi ilmu pengetahuan. Karena prinsip tauhid merupakan prinsip yang digunakan sebagai kerangka pemikiran, metodologi dan cara hidup Islami. Prinsip tauhid tersebut dikembangkan menjadi: ${ }^{13}$
a. Kesatuan Tuhan,
b. Kesatuan ciptaan,
c. Kesatuan kebenaran dan Pengetahuan,
d. Kesatuan kehidupan,
e. Kesatuan kemanusiaan.

\section{Proses Islamisasi}

\section{Syed Muhammad Naquib Al-Attas}

Al-Attas menjelaskan bahwa ada dua cara yang saling terkait di dalam pelaksanaan Islamisasi ilmu, yaitu: ${ }^{14}$

1. Mengisolisir unsur-unsur dan konsep-konsep kunci yang membentuk budaya dan peradaban barat.

2. Memasukkan unsur-unsur Islam beserta konsep-konsep kunci dalam setiap bidang dari ilmu pengetahuan saat ini yang relevan.

Unsur-unsur tetsebut menurut al-Attas, ada lima faktor yang menjiwai budaya dan peradaban Barat yaitu akal yang diandalkan untuk membimbing kehidupan manusia; bersikap dualistik terhadap realitas dan kebenaran; menegaskan aspek eksistensi yang memproyeksikan pandangan hidup sekuler; membela doktrin humanisme; menjadikan drama dan tragedi sebagai unsur-unsur yang dominan dalam fitrah kemanusiaan..$^{15}$ unsur-unsur tersebut harus dihilangkan tertama dalam bidang ilmu humaniora begitu juga dalam ilmu lainnya. Kemudian dimasukkan konsep-konsep

${ }^{11}$ Zuhdiyah, "Islamisasi Ilmu Ismail Raji Al-Faruqi", Hlm.9

12 Muhammad Taufik Dan Muhammad Yasir, "Mengkritisi Konsep Islamisasi Ilmu Ismail Raji Al-Faruqi: Telaah Pemikiran Ziauddin Sardar", Hlm.121

${ }^{13}$ Salafudin, "Islamisasi Ilmu Pengetahuan", Forum Tarbiyah Vol. 11, No. 2, Desember 2013, Hlm.208-209

14 Muhammad Taufik Dan Muhammad Yasir, "Mengkritisi Konsep Islamisasi Ilmu Ismail Raji Al-Faruqi: Telaah Pemikiran Ziauddin Sardar", Hlm. 114

15 Ismail Thoib Dan Mukhlis, "Dari Islamisasi Ilmu Menuju Pengilmuan Islam: Melawan Hegemoni Epistemologi Barat" Ulumuna Jurnal Studi Keislaman, Volume 17 Nomor 1 (Juni) 2013, Hlm.74 
kunci Islam yaitu: konsep Agama, konsep manusia, konsep pengetahuan, konsep kearifan, konsep keadilan, konsep perbuatan yang benar yang semuanya berkaitan dengan konsep tauhid.

\section{Isma'Il Raji Al-Faruqi}

Dalam merealisasikan proses Islamisasi ilmu pengetahuan tersebut Al-Faruqi menetapkan tujuan dalam kerangka kerjanya yaitu: Penguasaan disiplin ilmu modern, Penguasaan khazanah Islam, Membangun relevansi Islam dengan masing-masing disiplin ilmu modern, Memadukan nilai-nilai dan khazanah warisan Islam secara kreatif dengan ilmu-ilmu modern, dan Pengarahan aliran pemikiran Islam ke jalan-jalan yang mencapai pemenuhan pola rencana Allah. ${ }^{16}$

Kemudian tujuan tersebut di realisasikan melalui langkah-langkah isllamisasi ilmu pengetahuuan yaitu sebagai berikut: ${ }^{17}$

a. Penguasaan disiplin ilmu modern: prinsip, metodologi, masalah, tema dan perkembangannya,

b. Survei disiplin ilmu,

c. Penguasaan khazanah Islam: sebuah ontologi,

d. Penguasaan khazanah ilmiah Islam: tahap analisis,

e. Penentuan relevansi Islam yang khas terhadap disiplin-disiplin ilmu,

f. Penilaian secara kritis terhadap disiplin keilmuan modern dan tingkat perkembangannya di masa kini,

g. Penilaian secara kritis terhadap khazanah Islam dan tingkat perkembangannya dewasa ini,

h. Survei permasalahan yang dihadapi umat Islam,

i. Survei permasalahan yang dihadapi manusia,

j. Analisis dan sintesis kreatif,

k. Penuangan kembali disiplin ilmu modern ke dalam kerangka Islam, dan

1. Penyebarluasan ilmu yang sudah diislamkan

\section{Analisis Konsep Islamisasi Ilmu Pengetahuan Al-Attas dan Al-Faruqi}

Islamisasi Al-Attas dan Al-Faruqi memiliki kesamaan dalam pemikirannya yaitu keduanya menganggap bahwa masalah utama dari krisis umat Islam adalah ilmu pengetahuna yang

${ }^{16}$ Zuhdiyah, "Islamisasi Ilmu Ismail Raji Al-Faruqi", Hlm.10

${ }^{17}$ Salafudin, "Islamisasi Ilmu Pengetahuan", Hlm. 209 
kembangkan Barat. Begitupun mengenai konsep ilmu keduanya menganggap ilmu sebenarnya tidak bebas nilai namun sebaliknya sarat akan nilai yang mana konsep ilmu seharunya berlandaskan prinsip dan nilai-nilai Islam. Sedngakan jika dilihat dari konsep Islamisasinya AlAttas lebih mengutamakan Islamisasi pemikiran manusia yaitu pemikiran manusia harus dibebaskan dari nilai-nilai sekuler. Sedangkan Al-Faruqi lebih kepada sistem yang harus di Islamkan atau yang menjadi objeknya,

Dalam proses Islamisasi Al-Attas menggunakan dua langkah yatu mengisolasi konsep yang tidak sesuai dengan nilai dan prinsip dalm Islam kemudian memasukkan kedalamnya konsep utama dalam Islam. Langkah Islamisasi ini lebih mudah dipahami dan dapat diterapakn disegala kegiatan yang mengandung konsep sekuler oleh semua orang. Sedangkan Al-Faruqi menggunakan dua belas langkah dalam proses Islamisasi agar dapat melakukan Islamisai secara menyeluruh, namun dengan konsep Islamisasi ini tidak semua orang dapat menerapkannya. Tidak semua orang dapat menguasai ilmu pengetahuan Barat sekaligus ilmu pengetahuan Islam.

Al-Attas membatasi objek yang harus diIslamkan yaitu ilmu pengetahuan kontemporer saja karena ilmu pengetahuan kontemporerlah yang menurutnya berisi ide-ide, nila-nilai, kebudayaan, keyakina, filsafat, agama, doktrin berupa spekulasi yang semuanya bertentangan dengan nilai-nilai dalam Islam. Sedangkan Al-Faruqi menganggap semua ilmu pengetahuan harus diIslamkan.

\section{KESIMPULAN}

Latar belakang munculnya gagasan Islamisai menurut Al-Attas karena ilmu pengetahuan kontemporer mengandung nilai-nilai sekuler yang bertentangan dengan nilai-nilai dalam Islam sehingga penerapannya dalam kehidupan umat Muslin mebawa dampak negatif. Menurut AlFaruqi akibat dari penggunaan sistem sekuler dalam pendidikan Islam umat Muslim mengalami kebingunagn dan kehilangan visinya. Untuk itu dari kedua alasan tersebut muncullah gagasan Islamisasi untuk mengembalikan kejayaan Umat Islam

Menurut Al-Attas islamisasi adalah Islamisasi adalah pembebasan manusia pertama dari magis, mitologis, animistis, nasional-kultur, dan kemudian dari kontrol sekuler atas nalar dan bahasanya. Sedangkan menurut al-Faruqi, Islamisasi ilmu pengetahuan itu sendiri berarti melakukan aktifitas keilmuan seperti eliminasi, perubahan, penafsiran kembali dan penyesuaian terhadap komponen-komponennya sebagai world view Islam dan menetapkan nilai-nilainya.

Al-Attas menggunakan dua langkah Islamisasi yairu mengisolasi konsep yang tidak sesuai kemudian memasukkan konsep kunci Islam yang sesuai kedalamnya. Al-Faruqi menggunakan kerangka kerja yang memiliki dua belas langkan yang terdiri dari penguasaan ilmu pengetahuan Barat dan ilmu pengetahuan Islam yang direformulasi agar sesuai dengan konsep Islam. 
Objek Islamisasi Al-Attas dibatasi untuk ilmu pemgetahuan Barat kontemporer sedangkan Al-Faruqi beranggapan bahwa semua ilmu pengetahuan harus diIslamkan.

\section{REFERENSI}

Afifah, Ni'Mah. Islamisasi Ilmu Pengetahuan Perspektif Naquib Al-Attas Di Tengab Kemunduran Dunia Ilmiah Islam. Modeling: Jurnal Program Studi Pgmi.

Al-Attas, Syed Muhammad Naquib. 1978. Islam And Secularism. Kuala Lumpur, Art Printing Works Sdn. Bhd, Istac.

Al-Attas, Syed Muhammad Naquib. 1980. The Consept Of Education In Islam. (Malaysia:International Institute Of Islamic Thought And Civilization (Istac).

Mauliyah, Anita. 2016. Gerakan Islamisasi Ilmu Pengetabuan Naquib Al-Attas. El-Banat: Jurnal Pemikiran Dan Pendidikan Islam Volume 6, Nomor 1.

Salafudin. 2013. Islamisasi Ilmu Pengetahuan. Forum Tarbiyah Vol. 11, No. 2.

Sholeh. 2017. Islamisasi Ilmu Pengetabuan (Konsep Pemikiran Ismail Raji Al-Faruqi Dan Syed Muhammad Naquib Al-Attas). Jurnal Al-Hikmah Vol. 14, No. 2.

Taufik, Muhammad Dan Muhammad Yasir. 2017. Mengkritisi Konsep Islamisasi Ilmu Ismail Raji AlFaruqi: Telaah Pemikiran Ziauddin Sardar. Jurnal Ushuluddin Vol. 25 No.2.

Thoib, Ismail Dan Mukhlis. 2013. Dari Islamisasi Ilmu Menuju Pengilmuan Islam: Melawan Hegemoni Epistemologi Barat. Ulumuna Jurnal Studi Keislaman, Volume 17 Nomor 1.

Zuhdiyah. 2016. Islamisasi Ilmu Ismail Raji Al-Faruqi. Tadrib Vol. Ii No. 2 . 